\title{
Flyers Tooth Squeeze - Current Concepts and Future Needs - A Review
}

\author{
Sohaib Arshad ${ }^{1}$, Soha Shawqi Albayat ${ }^{2}$, Sameer Badri Al-Mhanna ${ }^{3}$, Raja Azman Awang ${ }^{4}$, Hina Abbas ${ }^{5}$, Fatima Tehreem ${ }^{6}$ \\ 1, 4, Periodontics Unit, School of Dental Sciences, Health Campus, Universiti Sains Malaysia, \\ Kubang Kerian 16150, Kelantan, Malaysia. ${ }^{2}$ Public Health Department, Ministry of Public Health, Doha, Qatar. \\ ${ }^{3}$ Department of Physiology, Health Campus, School of Medical Sciences, Universiti Sains Malaysia, Kubang \\ Kerian 16150, Kelantan, Malaysia. ${ }^{5}$ Biomaterials and Visualization 3D Laboratory, School of Dental Sciences, \\ Health Campus, Universiti Sains Malaysia, Kubang Kerian, 16150 Kota Bharu, Kelantan, Malaysia. ${ }^{6}$ FMH \\ College of Medicine and Dentistry, Shadman, Lahore, Pakistan.
}

\section{ABSTRACT}

\section{BACKGROUND}

The flyers tooth or the tooth squeeze is the toothache during air travel, termed as Barodontalgia / Aerodontalgia by researchers. It was first identified as an in-flight physiologic and pathologic phenomenon at the start of the 20th century. With the introduction of the scuba in the 1940s, many in-flight manifestations caused by barometric variations were discovered to be synonymous with diving as well. Scuba diving is a type of underwater diving where the diver breathes underwater using equipment independent of the surface supply. It can be performed for fun or a living in various settings, including the scientific, army, and public security responsibilities. However, most commercial diving employs surface-supplied diving equipment wherever possible. Battle divers and assault swimmers are all terms for scuba divers who participate in clandestine military operations. Most cases of barodontalgia occur during ascent. The origin of the discomfort is also affected by the underlying pathology. In general, pain on the rise is associated with essential pulp disease, i.e., pulpitis and pain on descent with pulp necrosis. The pain subsides typically as the patient returns to the onset stage or the ground ambient level, although it can last longer if exacerbated by periapical infection. The Fédération dentaire internationale FDI advises that pilots, divers, and other professionals undergo yearly exams, as well as appropriate dental hygiene education from dentists, after a dental procedure that necessitates an anaesthetic or seven days after a dental procedure until travelling, teeth with pre-existing substantial restorations should have a cold-test examination or periapical radiographs taken to rule out occult pulp necrosis. It is appropriate to arrange outpatient dental appointments for a suitable period until the next scheduled flight. The possible treatment modalities vary from immediate relief to the control of infection and further subsequent treatment procedures. In recent years, the airline industry and scuba diving have grown in popularity, but little is known about the oral issues linked with high altitude. It is entirely the obligation of dental health experts to give the finest dental care to aviators as well as raise knowledge of the risks of dental treatments at higher altitudes. Dentists and flight crew members should both have appropriate awareness of barodontalgia and its role in its prevention. Particular attention should be given by the otolaryngologist and must be aware of the issues and hazards associated with scuba diving.

\section{KEY WORDS}

Aerodontalgia, Barodontalgia, Flyer's Tooth, Pulpitis; Scuba, Tooth Squeeze
Corresponding Author: Dr. Raja Azman Awang, School of Dental Sciences, Health Campus, Universiti Sains Malaysia, Kubang Kerian, 16150 Kota Bharu, Kelantan, Malaysia. E-mail: rjazman@usm.my

DOI: $10.14260 /$ jemds/2021/695

How to Cite This Article: Arshad S, Albayat SS, Al-Mhanna SB et al. Flyers tooth squeeze - current concepts and future needs - a review. J Evolution Med Dent Sci 2021;10(38):3436-3440, DOI: 10.14260/jemds/2021/695

Submission 03-07-2021, Peer Review 05-09-2021, Acceptance 11-09-2021, Published 20-09-2021.

Copyright (C) 2021 Sohaib Arshad et al. This is an open access article distributed under Creative Commons Attribution License [Attribution 4.0 International (CC BY 4.0)] 


\section{BACKGROUND}

Recently, during an eight-hour long-haul flight, I developed a toothache in a visually sound tooth, which prompted me to investigate the underlying cause. Millions of people travel every day by air worldwide with different experiences, and toothache during air travelling is one of them, which was termed as "Barodontalgia" by researchers. Barodontalgia is an oral (dental or non-dental) pain caused by a change in barometric pressure in an otherwise asymptomatic organ. ${ }^{1}$ This dental pain was assigned the prefix "aero," previously known as (Aerodontalgia). It was first identified as an inflight physiologic and pathologic phenomenon at the start of the 20th century. With the introduction of scuba in the 1940s, many in-flight manifestations caused by barometric variations were discovered to be synonymous with diving as well. As a result, the prefix was changed to "baro." Because of hypobaria, acceleration, low humidity, thermal variation, turbulence, and other factors, aircraft has been defined as a "physiologically challenged environment."2 Rapid pressure changes are mostly the cause that is being controlled by the pressurization of aeroplane cabins which eventually aids in the reduction of barodontalgia. Literature suggests that the dentists face barodontalgia as an emergency due to increased scuba divers and frequent flying nowadays. Divers showed the involvement of maxillary teeth commonly, whereas both maxillary and mandibular teeth in flyers.

Recreational diving is becoming increasingly popular these days. More than $50 \%$ of the severe clinical complications with scuba diving are linked to otorhinolaryngology, with around $90 \%$ of these involving the ear. The issues can be connected to descent, ascent, or specific circumstances related to the depth or gas mixture utilized.3,4 According to the study, 402 (8.2\%) of the 4894 people tested had barodontalgia. Divers were more susceptible than aircrews (9.8\%). (5.8 percent). The rates of barodontalgia in the army and civil aircrews were 5.4 percent and 6.5 percent, respectively, and 7.3 percent and 12.8 percent in the army and civil scuba divers, respectively. Barodontalgia was more prevalent in pressurized flight crews than in non - pressurized aircraft personnel (7.3 percent vs. 3.2 percent, respectively). Therefore, scuba divers are the most prevalent casualties, as pressures can rise by several atmospheres during deep dives, ${ }^{5}$ due to the fast changes in the military pilots, and barodontalgia in pilots can be severe enough to force them to cancel flights.6-8 In the Israeli Air Force, the rate of barodontalgia was around one incidence per 100 flight - years. Approximately one-tenth of the American aircrews experienced one or more bouts of barodontalgia throughout the World War $2^{9} 8.2$ percent of 331 Israeli Air Force aircrews experienced at least one episode of barodontalgia as reported in recent research by ZADiK, CHApNiK. ${ }^{10}$ Hence, changes in barometric pressure were shown to be the cause of the onset and aggravation of different oral pains seen in dental emergency rooms, according to extensive clinical research. ${ }^{11}$

Most cases of barodontalgia occurred during ascent. The origin of the discomfort is also affected by the underlying pathology. In general, increased pain is associated with essential pulp disease, i.e., pulpitis and pain on descent with pulp necrosis. The pain subsides typically as the patient returns to the onset stage or the ground ambient level, although it can last longer if exacerbated by periapical infection. ${ }^{12}$ Dental caries, faulty tooth regeneration, pulpitis, pulp necrosis, apical periodontitis (jawbone cyst and granuloma), periodontal pockets, impacted teeth, and mucous retention cysts have all been identified causes of barodontalgia. Sinusitis may also contribute to these symptoms, although it is not related to tooth pathology.13

\section{Scuba and Barodontalgia}

Scuba diving is a type of underwater diving where the diver breathes underwater using equipment independent of the surface supply. ${ }^{14}$ It can be performed for fun or for a living in various settings, including the scientific, army, and public security responsibilities. However, most commercial diving employs surface-supplied diving equipment wherever possible. Battle divers and assault swimmers are the terms for scuba divers who participate in clandestine military operations. The namesake scuba, a self-contained underwater breathing device that lets the diver breathe while the diver is diving and, is the specific piece of equipment used by a scuba diver. During exposure to a higher pressure during a dive, inert gas components of the diver's respiration gas build in the tissues and should be removed during the ascent to avoid the development of symptomatic bubbles in tissues where the percentage is too high for the gas to remain in solution. This process is called decompression and occurs in all scuba divers. Itching, rash, joint discomfort, and nausea are all signs of decompression sickness, also described as the bends ${ }^{15}$

The discomfort and pain, the divers suffer due to barometric fluctuations, have been linked to a variety of oral pathologies, also identified as barodontalgia. ${ }^{16}$ However, when an individual is submerged, the pressure exerted by the water increases, causing the volume of gases in the pulp chamber and root canals to decrease. Scuba divers may experience dental problems, and the dentist should be aware of the pain which has been recorded at depths ranging from 30 to 80 feet. 17

Goossens and Van Heerden 18 indicated that upper teeth are more frequently impacted than lower teeth, and most cases develop when compressed air enters the dentin tubules or pulp through original caries or recurrent caries along the restoration's borders.

While Barotrauma occurs when pressurized air is confined in an enclosed area and then expands in different directions. As a result, this is apparent in incomplete RCT or ignored repair. In extreme conditions, ${ }^{19}$ the pressure in the tooth may build-up to the point where the tooth explodes, a condition known as odontecrexis. ${ }^{20}$ On examining the relation between oral issues such as periodontal discomfort and scuba diving among 150 divers, found that nine people (6.3\%) had gum disorders, with the most frequent issues being shooting pain $(\mathrm{N}=4)$ and tooth sensitivity $(\mathrm{N}=3)$, furthermore, depending on age, gender, or diving rate. Other forms of discomfort, such as headache (49 percent), sinus pain (32.2 percent), and jaw pain (22.1 percent), were more common among divers under 30 years of age $(\mathrm{N}=136)$ (16.2 percent). However, the author concluded that dental care should be given more attention to dental problems experienced by the divers such as toothache, headache, sinus pain, and jaw pain.

On the other hand, Tsur, Arbel ${ }^{21}$ investigated the comparison between the oral pathologies in military divers 1036 and non - divers 5362 of (mean age $=22.1$ years), found 
that divers had a significantly greater risk of faulty dental restorative dentistry than non - divers (9.3 percent vs. 6.7 percent), as well as divers, had a significantly higher prevalence of temporomandibular disorders, especially disc displacement without reduction ( 0.4 percent vs. 0.1 percent), in addition, divers were nine times more likely than non divers to have additional oral injuries.

\section{Classification}

In 1993 a researcher gave three hypotheses with histological evidence to expand air bubbles trapped under root canal filling or against the dentine, which activates nociceptors, due to referred pain from the teeth, which stimulates nociceptors in maxillary sinus or inflamed pulp stimulating the nerve ending. ${ }^{22}$ Barodontalgia is of two types, one direct and the other indirect. The direct one is from the pathology like periapical or the pupal lesions, whereas the indirect one is induced due to barotitis. In the year 1982, Ferjentsik and Aker classified barodontalgia into four types as follows: (Figure 1)

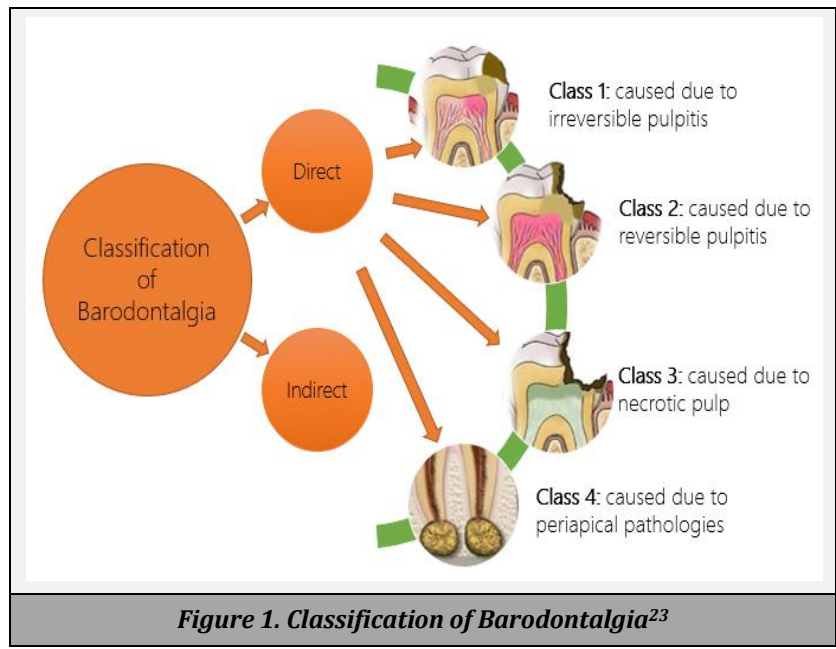

\section{Pathogenesis}

The leading cause for barodontalgia is inflammation in the pulp (pulpitis); many hypotheses have been proposed for the pathogenesis of barodontalgia. Table 1 shows the possible pathogenesis of barodontalgia.

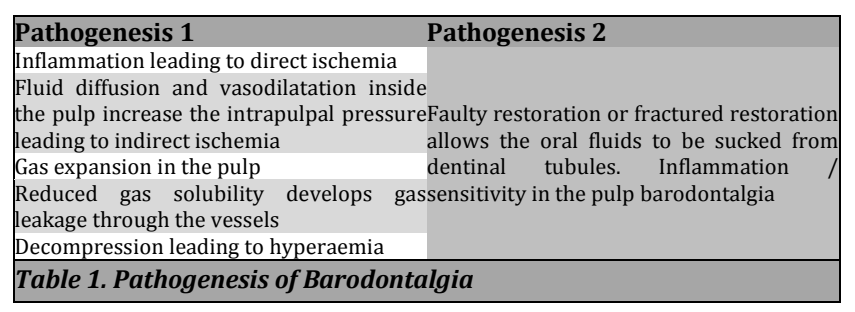

According to the new inside pressurization of airplane chambers, high - quality dental treatment, and improved oral hygiene, the incidences of in - flight dental manifestations of pressure changes are comparatively minimal (compared to recorded incidences from the first half of the twentieth century). Similarly conforming to published studies and academic reports, special attention should be paid to flawed (fractured or cracked) restorations, restorations with low stability, and secondary caries lesions. ${ }^{24}$
Until travelling, teeth with pre-existing substantial restorations should have a cold-test examination or periapical radiographs taken to rule out occult pulp necrosis. It is appropriate to arrange outpatient dental appointments for a suitable period until the next scheduled flight. Dentists must inform their aircrew and patients considering a trip of the postoperative flight consequences and limitations at the time of care planning.

\section{Preventive Measures}

An altitude of more than 5,000 feet can cause dental discomfort in any tooth, whether healthy or repaired. It is thought to be the result of a severe pressure shift. Despite improved flying conditions, the incidence has not decreased. For individuals who fly, such as civilians and military pilots, as well as airline passengers, this type of dental pain is a concern. The circumstances under which this may have occurred are diverse. ${ }^{25}$ There may be a direct link between the kind of aerodontalgia signs and the underlying pulpal disease. Oedema and heat of the pulp, which can develop into necrosis, are the hypothesized aetiologies for pathologic teeth. Indirect dental pain is caused by a maxillary barosinusitis or anatomic abnormality that stimulates the upper alveolar nerves. The most common symptom is ache during ascent (decompression), with upper molars being the most involved teeth. ${ }^{25}$ Therefore prevention and treatment are needed, Goethe, Bäter ${ }^{26}$ documented that divers, submariners, pilots, and airline passengers are all at risk of barodontalgia. The dental care varies from palliative to definitive; however, all teeth must be tested for vitality for the identification and treatment of asymptomatic pulp necrosis. The Fédération dentaire internationale FDI advises that pilots, divers, and other professionals undergo yearly exams, as well as appropriate dental hygiene education from dentists, after a dental procedure that necessitates an anaesthetic or seven days after a dental procedure. For the following 24 hours, patients should not dive deep or travel in non - pressurized cabins. ${ }^{27}$ When restoring a carious tooth, the doctor needs to carefully check the cavity floor to rule out pulp chamber penetration and use a cavity liner glass ionomer cement. Moreover, in high-risk groups, routine oral and dental exams, including periapical radiography and vitality tests, are suggested to avoid barodontalgia (e.g., aircrews, divers). Furthermore, screening panoramic radiographs at 3 - 5 year intervals is advised for these groups $^{28}$ as well as periapical pathosis, poor restorations, subsequent caries lesions, and indications of tooth attrition should all be given special consideration ${ }^{29}$ Hence the essential factor in preventing barodontalgia is maintaining proper dental hygiene. Caries excavation treatments and restorations, in addition to excellent dental hygiene, should be done. ${ }^{13}$

\section{Treatment Modalities}

Treatments that are advised to be carried out are those usually performed in the dental practice for example, if experiencing tooth squeeze, avoid diving until recovery is complete. Pain may be relieved with analgesics taken according to the recommended dose. The possible treatment modalities from immediate relief to the control of infection 
and further subsequent treatment procedures have been shown in Figure 2.30

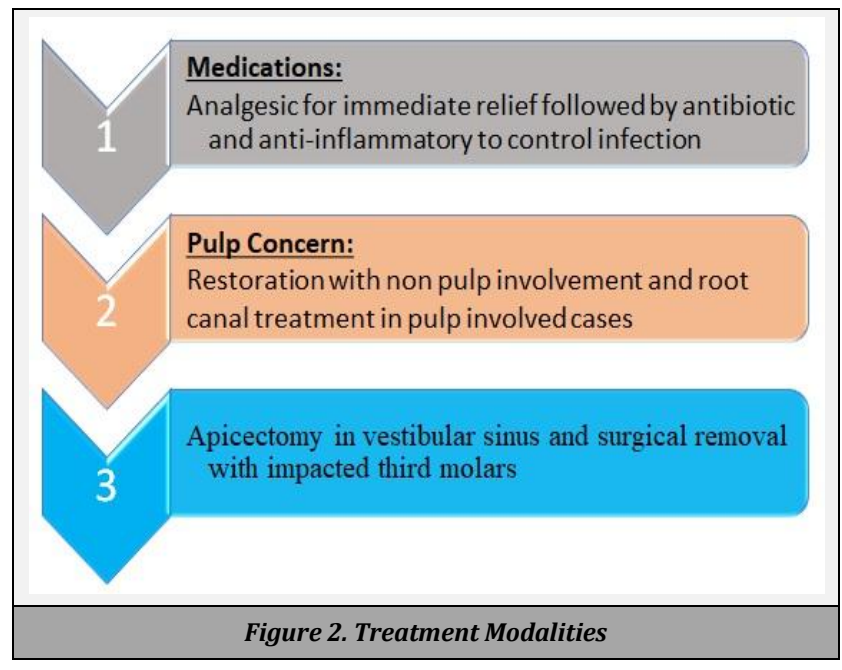

\section{Future Recommendations}

In recent years, the airline industry and scuba diving have grown in popularity, but little is known about the oral issues linked with high altitude. It is particularly common in frequent fliers, crew members, pilots, and other members of the aviation industry. Pressure builds up in these organs as a result of the confined chamber, producing pain, discomfort, and organ failure. Therefore, it is entirely the obligation of dental health experts to give the finest dental care to aviators as well as raise knowledge of the risks of dental treatments at higher altitudes. Dentists and flight crew members should both have appropriate awareness of barodontalgia and its role in its prevention.

Dental care is an essential element of an aircrew's operative fitness, which might be threatened by the lower air density and pressure at higher altitudes. Therefore it must be prioritized. As well as flight surgeons and clinicians must be aware of oral issues that arise as a result of the flight. However, even though dental breakage appears to be uncommon in the aircraft setting, it may be avoided by getting regular dental exams and paying enough attention to existing dental restorations. Hence, understanding those diseases and raising awareness of the limitations of current understanding about such problems will benefit the flying population.

We recommend that future research in the field of aircraft dentistry may be conducted, and aircrew representatives and frequent fliers should be subjected to a mandatory routine dental check-up before departure. In addition, particular attention should be given by the otolaryngologist and must be aware of the issues and hazards associated with scuba diving.

\section{CONCLUSIONS}

Barodontalgia is rather uncommon according to the literature and this issue was neglected in dental education and research in recent decades. This article is simply an overview of the topic. It should, however, increase awareness because recent research reveals that promising findings exist in almost every field of barodontalgia, from preventive strategies to surgical therapeutic techniques. Certain groups, such as air travellers, pilots, and scuba divers, have been recognised as having a greater risk of developing barodontalgia. The actual aetiology of barodontalgia and the causes of pain appear to be still a source of debate. Nonetheless, research has revealed effective methods for predicting, identifying, and treating the condition, perhaps preventing a tragedy. Factors like the influence of pressure gradient, sinuses or pathologies in oral tissues must co-exist for barodontalgia symptoms. To reduce the risk of developing barodontalgia, patients who are often exposed to fluctuations in ambient pressure should be urged to practise excellent oral hygiene, attend scheduled dental recall check-ups regularly, and embrace the timely completion of restorative treatment. In addition, doctors' treatment modalities must be well-planned and tailored to the specific needs of specialized people. Even though its prevalence has been documented for some time, extensive research to better understand barodontalgia would be beneficial for those who provide treatment. Moreover, barodontalgia continuing dental education sessions should be held regularly to keep students and dentists up to date on the latest concepts and practises in the field.

Financial or other competing interests: None.

Disclosure forms provided by the authors are available with the full text of this article at jemds.com.

\section{REFERENCES}

[1] Zadik Y. Aviation dentistry: current concepts and practice. British Dental Journal 2009;206(1):11-6.

[2] Butler WP, Steinkraus LW, Burlingame EE, et al. Clinical impact of cabin altitude restriction following aeromedical evacuation. Military Medicine 2018;183(Suppl 1):193-202.

[3] Robles-Avilés A. Papel del otorrinolaringólogo en el buceo SCUBA. Anales de Otorrinolaringología Mexicana 2020;65(2):80-91.

[4] Nakdimon I, Zadik Y. Performance, Barodontalgia among aircrew and divers. Aerosp Med Hum Perform 2019;90(2):128-31.

[5] Zadik Y, Drucker S. Diving dentistry: a review of the dental implications of scuba diving. Aust Dent J 2011;56(3):265-71.

[6] Brubakk AO, Neumann TS, Bennett PB, et al. Bennett and Elliott's Physiology and medicine of diving. Philadelphia, PA: Saunders Ltd., 2003.

[7] Lyons KM, Rodda JC, Hood JA. Barodontalgia: a review and the influence of simulated diving on microleakage and on the retention of full cast crowns. Mil; Med 1999;164(3):221-7.

[8] Del Mar GSM, Martinez-Sahuquillo MA, BullonFernandez P. Incidence of barodontalgias and their relation to oral/dental condition in personnel with responsibility in military flight. Med Oral 2004;9(2):98105, 92-8.

[9] Zadik Y. Aviation dentistry: current concepts and practice. British Dental Journal 2009;206(1):11-6.

[10] Zadik Y, Chapnik L, Goldstein L. In-flight barodontalgia: analysis of 29 cases in military aircrew. Aviation Space \& Environmental Medicine 2007;78(6):593-6. 
[11] Kloss-Brandstätterl A, Hachl O, Leitgeb PC, et al. Epidemiologic evidence of barometric pressure changes inducing increased reporting of oral pain. Eur J Pain 2011;15(8):880-4.

[12] Zadik Y. Barodontalgia due to odontogenic inflammation in the jawbone. Aviation, Space and Environmental Medicine 2006;77(8):864-6.

[13] Praveena R. Pressure provoking pain-barodontalgia: an overview. 2021. https://www.openacessjournal.com/abstract/656

[14] Navy US. US Navy Diving Manual. 6th Revision. United States: US Naval Sea Systems Command 2006: p. 2-32. Retrieved 15-06-2008.

[15] Melissa CS. Symptoms and signs of the bends (Decompression Syndromes). 2019.

[16] Robichaud R, McNally ME. Barodontalgia as a differential diagnosis: symptoms and findings. J Can Dent Assoc 2005;71(1):39-42.

[17] Jagger RG, Shah CA, Weerapperuma ID, et al. The prevalence of orofacial pain and tooth fracture (odontocrexis) associated with SCUBA diving. Prim Dent Care 2009;16(2):75-8.

[18] Goossens I, van Heerden WF. Interpretation and management of oral symptoms experienced by scuba divers. J of the South African Dental Association 2000;55(11):628-31.

[19] Zadik Y. Barodontalgia. J of Endodontics 2009;35(4):481-5.

[20] Shshtari H, Chatzopoulou D, Gillam DG. The prevalence of periodontal pain associated with scuba diving: a Questionnaire study. ES Journal of Dental Sciences 2020;1(1):1002.
[21] Tsur N, Arbel Y, Abuhasira S, et al. A retrospective study of oral pathoses in Israeli military divers and non-divers: 2011-2020. Dent Traumatol 2021.

[22] Kollmann W. Incidence and possible causes of dental pain during simulated high altitude flights. Journal of Endodontics 1993;19(3):154-9.

[23] Ferjentsik E, Aker F. Barodontalgia: a system of classification. Military Medicine 1982;147(4):299, 303-4.

[24] Zadik Y, Chapnik L, Goldstein L. In-flight barodontalgia: analysis of 29 cases in military aircrew. Aviation Space \& Environmental Medicine 2007;78(6):593-6.

[25] Fleury JE, Deboets D, Voisin D, et al. Aerodontalgia. Report of a case. Rev Stomatol Chir Maxillofac 1988;89(1):15-20.

[26] Goethe WH, Bäter H, Laban C. Barodontalgia and barotrauma in the human teeth: findings in navy divers, frogmen and submariners of the Federal Republic of Germany. Mil Med 1989;154(10):491-5.

[27] Jayasrikrupaa R, Mystica T, AravindhaBabu N, et al. Barodontalgia-an agony for the tooth. European J Molecular and Clinical Medicine 2020;7(3):1827-31.

[28] Kini PV, Jathanna VR, Shetty K, et al. Barodontalgia: etiology, features and prevention. Open J of Dentistry and Oral Medicine 2015;3(2):35-8.

[29] Lurie O, Zadik Y, Einy S, et al. Bruxism in military pilots and non-pilots: tooth wear and psychological stress. Aviat Space Environ Med 2007;78(2):137-9.

[30] Pathak S. Aviation dentistry: past to present. J Dental Research and Review 2015;2(3):138-40. 